\title{
Anatomia de raízes de nove espécies de Bromeliaceae (Poales) da região amazônica do estado de Mato Grosso, Brasil ${ }^{1}$
}

\author{
Ivone Vieira da Silva ${ }^{2,4}$ e Vera Lucia Scatena ${ }^{3}$
}

Recebido em 10/01/2011. Aceito em 15/06/2011

\section{RESUMO}

(Anatomia de raízes de nove espécies de Bromeliaceae (Poales) da região amazônica do estado de Mato Grosso, Brasil). Este estudo busca caracterizar raízes de Bromeliaceae: Aechmea bromeliifolia, A. castelnavii, A. mertensii (Bromelioideae), Dyckia duckei, D. paraensis, D. racemosa (Pitcairnoideae), Tillandsia adpressiflora, T. didistachae e T. paraensis (Tillandsioideae) ocorrentes nas regiões amazônicas (Mato Grosso-MT), procurando levantar caracteres de valor taxonômico e significado ecológico. As espécies estudadas são epífitas e suas raízes se caracterizam por apresentar velame pluriestratificado, córtex diferenciado, endoderme e periciclo unisseriados, cilindro vascular poliarco e medula com células de paredes espessadas. Estruturas anatômicas como: número de camadas e tipo de espessamento das paredes das células do velame, tipo de espessamento de parede da exoderme e endoderme, presença de idioblastos contendo cristais e número de pólos de protoxilema agrupam as espécies nos diferentes gêneros e subfamílias. A presença de canais de mucilagem no córtex de A. castelnavii relatados pela primeira vez na literatura para Bromeliaceae é caráter diagnóstico. As raízes de Dyckia e Tillandsia apresentam maior número de caracteres comuns, representando maior similaridade entre Pitcairnioideae e Tillandsioideae. Raízes com velame, exoderme com células de paredes espessadas constituindo uma camada mecânica, canais de mucilagem, lacunas de ar no córtex interno e idioblastos com cristais são estruturas adaptativas ao hábito epifítico.

Palavras-chave: Aechmea, Bromelioideae, canais de mucilagem, Dyckia, Pitcairnioideae, Tillandsia, Tillandsioideae, velame

\begin{abstract}
(Anatomy of the roots of nine species of Bromeliaceae (Poales) from the Amazon, Mato Grosso, Brazil). This study aimed to characterize the roots of Bromeliaceae, Aechmea bromeliifolia, A. castelnavii, A. mertensii (Bromelioideae), Dyckia duckei, D. paraensis, D. racemosa (Pitcairnoideae), Tillandsia adpressiflora, T. didistachae and T. paraensis (Tillandsioideae), that occur in Amazonian regions (Mato Grosso-MT), in order to find features of taxonomic value and ecological importance. The studied species are epiphytes and their roots are characterized by a multi-layered velamen, differentiated cortex, uniseriate endodermis and pericycle, polyarch vascular cylinder and medulla with thickened cell walls. Anatomical structures, such as the number of layers and kind of cell wall thickening of the velamen, the kind of thickening of the exodermis and endodermis walls, the presence of idioblasts containing crystals and the number of protoxylem poles help seperate these species within different genera and subfamilies. The presence of mucilage canals in the cortex of A. castelnavii is a diagnostic feature. The roots of Dyckia and Tillandsia share more common features, so there is greater similarity between Pitcairnioideae and Tillandsioideae. Roots with velamen, an exodermis with thickened cell walls constituting a mechanical layer, mucilage canals, air gaps in the inner cortex and idioblasts with crystals are structures adapted to the epiphytic habit.
\end{abstract}

Key words: Aechmea, Bromelioideae, mucilage canals, Dyckia, Pitcairnioideae, Tillandsia, Tillandsioideae, velamen

\footnotetext{
1 Parte da tese de Doutorado da primeira Autora

2 Universidade do Estado do Mato Grosso, Departamento de Biologia, Alta Floresta, MT, Brasil

3 Universidade Estadual Paulista, Departamento de Botânica, Instituto de Biociências, Rio Claro, SP, Brasil

4 Autor para correspondência: ivibot@hotmail.com
} 


\section{Introdução}

Bromeliaceae é considerada basal dentro de Poales (Stevens 2008), possuindo aproximadamente 56 gêneros e mais de 3000 espécies (Luther 2006). Atualmente seus representantes estão distribuidos em oito subfamílias (Givnish et al. 2008), e os gêneros Aechmea (Bromelioideae), Dyckia (Pitcairnioideae) e Tillandsia (Tillandsioideae) estão mantidos nas mesmas categorias taxonômicas reconhecidas anteriormente (Smith \& Downs 1974, Dahlgren et al. 1985).

Os representantes de Bromelioideae podem ser terrestres e/ou epífitas, apresentando sementes envolvidas por mucilagem dispersadas por animais e raízes voltadas à fixação, enquanto que os de Pitcairnioideae podem ser terrestres e epífitas contendo sementes aladas, dispersadas pelo vento, com raízes voltadas à absorção e os de Tillandsioideae predominantemente epífitas, com sementes plumosas e dispersadas pelo vento e raízes voltadas à fixação (Benzing 2000). Análises filogenéticas da família não confirmam o monofiletismo de Pitcairnioideae (Horres et al. 2000, Barfuss et al. 2005).

Bromeliaceae podem apresentar raízes intracorticais caulinares e externas (Tomlinson 1969). Numa compilação anatômica sobre representantes de diferentes gêneros de Bromeliaceae, Tomlinson (1969) indica que as raízes apresentam um padrão estrutural com exoderme pluriestratificada formando cilindro esclerótico e as demais células do córtex com paredes finas que podem se colapsar na maturidade e formar lacunas de ar. Ainda segundo o autor, as raízes apresentam células contendo amido, idioblastos com ráfides, endoderme unisseriada com as paredes das células igualmente espessadas ou com espessamento em "U", periciclo com uma ou duas camadas de células, de paredes finas e cilindro vascular com medula constituída de células de paredes espessadas.

As raízes como os demais órgãos de Bromeliaceae apresentam estratégias adaptativas, principalmente associadas ao hábito epifítico (Pita \& Menezes 2002, Segecin \& Scatena 2004, Proença \& Sajo 2008). Antigamente as raízes eram consideradas apenas como órgão de fixação com organização interna relativamente estável (Krauss 1948, Tomlinson 1969). Atualmente é atribuída a essas raízes a função de absorção, além da fixação, que é acompanhada de adaptações morfológicas (Proença \& Sajo 2008).

Vários estudos com raízes de Bromeliaceae são apresentados na literatura sob o ponto de vista anatômico (Krauss 1949, Tomlinson 1969, Pita \& Menezes 2002, Segecin \& Scatena 2004, Proença \& Sajo 2008), buscando relacionar a ocorrência de determinadas estruturas ao hábito e forma de crescimento dessas plantas e/ou ao ambiente onde elas vivem.

As circunscrições das subfamílias de Bromeliaceae e as relações entre os gêneros são pouco estáveis e necessitam de estudos variados com a finalidade de agregar mais informações que possam contribuir com um arranjo mais preciso de seus táxons (Brown \& Terry 1992). Neste sentido, o ob- jetivo desse trabalho é levantar características anatômicas das raízes que contribuam para a delimitação taxonômica dos gêneros e espécies e possibilitem evidenciar estratégias adaptativas de representantes de Bromeliaceae. Para tanto, escolheu-se espécies de Aechmea (Bromelioideae), Dyckia (Pitcairnioideae) e Tillandsia (Tillandsioideae) que ocorrem na região amazônica do estado de Mato Grosso, Brasil.

\section{Material e métodos}

As espécies de Bromeliaceae foram coletadas no Parque Estadual Cristalino e no seu entorno, em regiões amazônicas do estado de Mato Grosso. As espécies de Aechmea e Tillandsia estudadas são epífitas de árvore localizadas em clareiras, as espécies de Dyckia, rupícolas. Todos os indivíduos coletados ficam expostos completamente ao sol. Parte do material coletado foi herborizado e parte foi fixado em FAA 50 e estocada em etanol 70\% (Johansen 1940).

As exsicatas estão depositadas no Herbário da Universidade Estadual de Mato Grosso (HERBAN) sob os números: Aechmea bromeliifolia (Rudge) Baker 444, Aechmea casteInavii Baker 442, Aechmea mertensii (Meyer) Schult. 445; Dyckia duckei L.B. Smith 1231, Dyckia paraensis L.B. Smith 1245, Dyckia racemosa Baker 1259; Tillandsia adpressiflora Mez 2011, Tillandsia didistachae E. Morren Baker 2015 e Tillandsia paraensis Mez 2021.

Para o estudo anatômico das raízes, as amostras foram obtidas de pelo menos três indivíduos de cada espécie, coletadas em populações diferentes, em raízes totalmente desenvolvidas, a cerca de um centímetro a partir do rizoma.

Secções transversais foram obtidas à mão livre, com o auxílio de lâmina de barbear, clarificadas, coradas com azul de astra e fucsina básica (Roeser 1962) e montadas em lâminas histológicas semipermanentes com gelatina glicerinada (Kaiser 1880). Para as raízes de Aechmea castelnavii foram feitas secções transversais seriadas em raízes jovens e adultas afim de, estudar os canais de mucilagem.

Algumas secções de material fresco foram utilizadas para os testes histoquímicos, com Lugol para identificar amido, Sudan IV para lipídios, solução de Floroglucina em meio ácido e Safranina para lignina, Azul de Astra para celulose (Johansen 1940), reagente de Steinmetz para reconhecimento de constituintes celulares, tais como amido, celulose, lignina, suberina, lipídeos diversos, látex, gomoresina e cutina (Costa et al. 2002) e confirmando com o Cloreto de Zinco Iodado (Costa 1972), tionina (Costa 1972) e solução de Azul de Metileno para verificar presença de mucilagem (Langeron 1949).

\section{Resultados}

Nas espécies de Dyckia e Tillandsia estudadas ocorrem raízes caulinares intracorticais que apresentam estruturas semelhantes às das raízes externas e por isso, serão apre- 
sentadas apenas as raízes externas de todas as espécies estudadas.

As raízes apresentam velame, córtex diferenciado, endoderme e periciclo unisseriados e cilindro vascular poliarco (Fig. 1-9). O velame varia quanto ao número de camadas celulares e quanto à estrutura de suas paredes (Tab. 1) (Fig. 10-15). Apenas em Tillandsia adpressiflora e T. didistachae ocorre velame com células de paredes espessadas regularmente, e com depósito de lignina (Fig. 7, 8). Nas demais espécies, o velame apresenta células com paredes finas, de forma variável, desde arredondadas até irregulares (Fig. 1015). Em Aechmea mertensii o espessamento da parede das células do velame se dá por depósitos de faixas helicoidais da parede secundária (Fig. 13). Nas células do velame também ocorrem sinuosidade de parede em todas as espécies estudadas (Fig. 14, 15).

A camada periférica do velame está diferenciada em epivelame em Aechmea bromeliifolia (Fig. 10) e nas espécies de Tillandsia (Fig. 7, 8). Nas espécies estudadas ocorrem pelos absorventes unicelulares como observados nas três espécies de Aechmea (Fig. 10, 11, 12), em Dyckia duckei (Fig. 14) e D. paraensis (Fig. 3).

Nas espécies de Aechmea o número de camadas do velame varia de duas a cinco (Fig. 10,11, 13), nas de Dyckia de sete a dez (Fig. 14,15) e nas de Tillandsia de cinco a seis camadas (Fig. 7-9).

O córtex das raízes é diferenciado em externo, mediano e interno (Fig. 1-9), exceto em Tillandsia adpressiflora (Fig. 7) e T. didistachae (Fig. 8) onde quase não se observa diferenciação entre o córtex mediano e interno. $\mathrm{O}$ córtex externo é a exoderme, que é uniestratificada em Aechmea castelnavii (Fig. 11) e A. mertensii (Fig. 13); pluriestratificada com três camadas de células em Dyckia duckei (Fig. 14), Tillandsia adpressiflora (Fig. 7) e T. didistachae (Fig. 8); com quatro camadas de células em Aechmea bromeliifolia (Fig. 10) e Dyckia paraensis (Fig. 15) e; com sete e acima de sete camadas em D. racemosa e T. paraensis (Fig. 9).

Em Aechmea mertensii a exoderme apresenta células de paredes periclinais externas e paredes anticlinais mais espessadas que as demais, formando espessamento em " $U$ " invertido (Fig. 13). Nas demais espécies o espessamento das paredes das células da exoderme é homogêneo, tipo "O", com o lume das células reduzido (Fig. 1, 3, 5, 6, 10,14, 15).

Em todas as espécies estudadas o córtex mediano é constituído por células de paredes delgadas, com número variado de camadas de células isodiamétricas (Fig. 1-9). O córtex interno apresenta células parenquimáticas com espaços intercelulares conspícuos (Fig. 1-6, 9), essas células geralmente apresentam grãos de amido, e nesta região, se formam lacunas de ar (Fig. 1, 3, 5).

Chamam atenção os canais de mucilagem que ocorrem em anéis com espessamentos descontínuos na região cortical das raízes de Aechmea castelnavii (Fig. 2, 16, 17). Em diferentes fases de desenvolvimento da raiz (Fig. 1821) observa-se nesses canais epitélio unisseriado envolto por uma bainha dupla (Fig. 18, 19). Conforme a raiz vai atingindo a maturidade as paredes das células da bainha tornam-se espessadas (Fig. 20, 21). Na maturidade, esses canais apresentam lume reduzido (Fig. 2, 16, 17, 21). Durante as diferentes fases de desenvolvimento da raiz e dos canais de mucilagem observa-se o afastamento das células, constituindo canal esquizógeno (Fig. 18-21). Apenas na raiz adulta de Aechmea castelnavii observa-se o felogênio (Fig. 17) que vai atuar na formação do revestimento.

Idioblastos contendo cristais de ráfides (Fig. 23) e drusas (Fig. 11,24) ocorrem no córtex e algumas vezes também no cilindro vascular das raízes de Aechmea e Tillandsia. A distribuição desses idioblastos é esparsa no córtex de Aechmea mertensii e A. bromeliifolia e mais acentuada no córtex mediano de A. castelnavii.

A endoderme, camada mais interna do córtex, é uniestratificada em todas as espécies estudadas (Fig. 25-31). Tanto as paredes periclinais quanto as anticlinais da endoderme de Aechmea castelnavii e das espécies de Tillandsia apresentam espessamento homogêneo, constituindo o espessamento em "O" (Fig. 25, 27, 28). Na endoderme das raízes, ocorrem células de paredes delgadas que estão localizadas opostamente aos pólos de protoxilema, são as células de passagem (Fig. 25, 27). Em Aechmea bromeliifolia (Fig. 29) e nas Dyckia (Fig. 30,31) a endoderme possui células com espessamento apenas nas paredes anticlinais e em A. mertensii (Fig. 26) além das paredes anticlinais, a periclinal interna também é espessada constituindo o espessamento em " $U$ ".

O cilindro vascular é delimitado pelo periciclo, que é unisseriado com células de paredes delgadas na maioria das espécies estudadas (Fig. 26-28, 30, 31), exceto em Aechmea castelnavii (Fig. 25) e Aechmea bromeliifolia que apresenta células de paredes parcialmente espessadas, alternando com células de parede delgadas.

Nas raízes de todas as espécies estudadas nota-se cilindro vascular com estrutura poliarca, formado por cordões de xilema alternados com cordões de floema (Fig. 25-31). O protoxilema em média apresenta 11 pólos nas Aechmea (Fig. 2), 12 a 19 pólos nas Tillandsia (Fig. 7, 8) e de 13 a 15 pólos nas Dyckia (Fig. 6). A medula das raízes é constituída de parênquima com células de paredes totalmente espessadas (Fig. 26, 32).

Os testes histoquímicos deram negativos para amido, gotas lipídicas, látex, gomo-resina e cutina para as raízes de todas as espécies estudadas. A tabela 1 agrupa as características anatômicas das raízes das espécies estudadas para facilitar a comparação entre gêneros e auxiliar na discussão.

\section{Discussão}

As espécies de Bromeliaceae cujas raízes foram estudadas estão distribuídas nas três subfamílias (Givnish et al. 2008): Aechmea (Bromelioideae), Tillandsia (Tillandsioideae) e Dyckia (Pitcairnioideae). Essas raízes apresentam estrutura anatômica semelhante as já citadas para a família 




Figuras 1-6. Secções transversais de raízes de Bromeliaceae. Aspecto geral de: 1. Aechmea bromeliifolia; 2. Aechmea castelnavii (Seta- canais de mucilagem); 3. Dyckia paraensis; 4. Aechmea mertensii; 5. Dyckia duckei; 6. Dyckia racemosa. (ce-córtex externo; ci-córtex interno; cm-córtex mediano; cv-cilindro vascular; ve-velame). (cabeças de setas- canais de mucilagem). Barras $=150 \mu \mathrm{m}(1-6)$. 


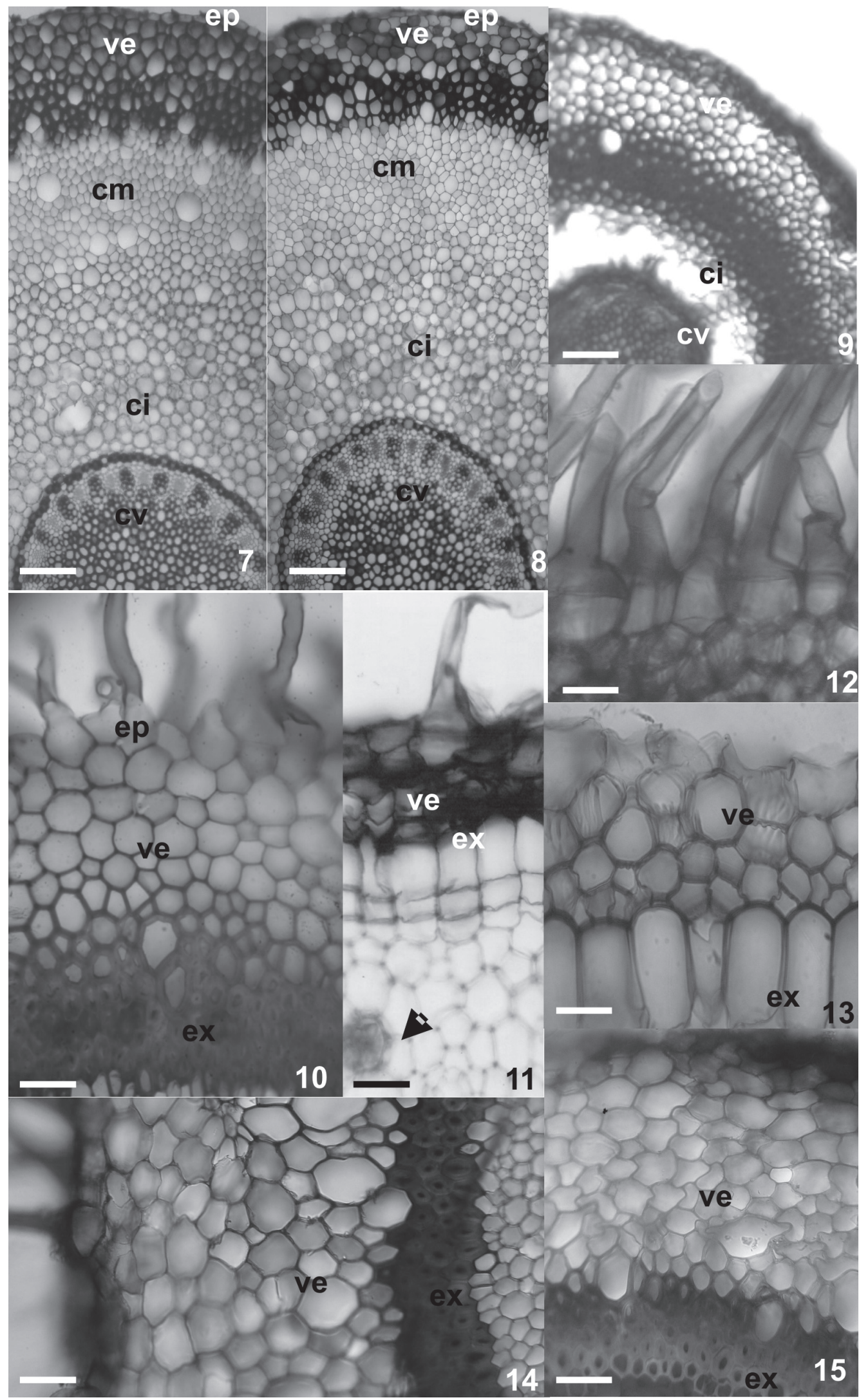

Figuras 7-15. Secções transversais de raízes de Bromeliaceae. Aspecto geral de: 7. Tillandsia adpressiflora; 8. Tillandsia didistachae; 9. Tillandsia paraensis. 10. Detalhe do velame e exoderme de Aechmea bromeliifolia. 11. Detalhe do velame, exoderme e drusa (cabeça de seta) no córtex de Aechmea castelnavii. 12-13. Detalhe do velame com células de paredes espessadas com faixas helicoidais de Aechmea mertensii. 14. Detalhe do velame e exoderme de Dyckia duckei. 15. Dyckia paraensis. (ci-córtex

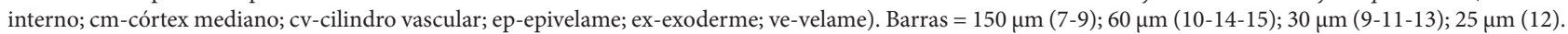


Tabela 1. Características anatômicas de raízes de espécies de Bromeliaceae: 1- Aechmea bromeliifolia, 2- A. castelnavii, 3- A. mertensii, 4- Dyckia duckey, 5- D. paraensis, 6- D. racemosa, 7- Tillandsia adpressiflora, 8- T. didistachae, 9- T. paraensis.

\begin{tabular}{|c|c|c|c|c|c|c|c|c|c|}
\hline \multirow[b]{2}{*}{ Características } & \multicolumn{3}{|c|}{ Aechmea } & \multicolumn{3}{|c|}{ Dyckia } & \multicolumn{3}{|c|}{ Tillandsia } \\
\hline & 1 & 2 & 3 & 4 & 5 & 6 & 7 & 8 & 9 \\
\hline Velame com 2-4 camadas de células & & $\mathrm{x}$ & $\mathrm{X}$ & & & & & & \\
\hline Velame com 5 a 6 camadas de células & $\mathrm{X}$ & & & & & & $\mathrm{x}$ & $\mathrm{X}$ & $\mathrm{X}$ \\
\hline Velame com 7 a 10 camadas de células & & & & $\mathrm{X}$ & $\mathrm{X}$ & $\mathrm{X}$ & & & \\
\hline Espessamento de lignina das paredes das células do velame & & & & & & & $\mathrm{x}$ & $\mathrm{X}$ & \\
\hline Espessamento helicoidal das paredes das células do velame & & & $\mathrm{X}$ & & & & & & \\
\hline Aparecimento de felogênio na raiz adulta & & $\mathrm{x}$ & & & & & & & \\
\hline Córtex diferenciado em externo, mediano e interno & $\mathrm{X}$ & $\mathrm{x}$ & $\mathrm{X}$ & $\mathrm{X}$ & $\mathrm{X}$ & $\mathrm{X}$ & $\mathrm{x}$ & $\mathrm{X}$ & $\mathrm{X}$ \\
\hline Exoderme uniestratificada & & $\mathrm{x}$ & $\mathrm{X}$ & & & & & & \\
\hline Exoderme pluriestratificada & $\mathrm{x}$ & & & $\mathrm{X}$ & $\mathrm{X}$ & $\mathrm{X}$ & $\mathrm{x}$ & $\mathrm{X}$ & $\mathrm{X}$ \\
\hline Exoderme com células de paredes espessadas de forma homogênea & $\mathrm{X}$ & $\mathrm{X}$ & & $\mathrm{X}$ & $\mathrm{X}$ & $\mathrm{X}$ & $\mathrm{X}$ & $\mathrm{X}$ & $\mathrm{X}$ \\
\hline Exoderme com células de paredes espessadas em forma de "U" & & & $\mathrm{X}$ & & & & & & \\
\hline Presença de canais de mucilagem & & $\mathrm{X}$ & & & & & & & \\
\hline Córtex interno com lacunas de ar & $\mathrm{X}$ & $\mathrm{X}$ & $\mathrm{X}$ & $\mathrm{X}$ & $\mathrm{X}$ & $\mathrm{X}$ & $\mathrm{X}$ & $\mathrm{X}$ & $\mathrm{X}$ \\
\hline Presença de Idioblastos com cristais & $\mathrm{X}$ & $\mathrm{X}$ & $\mathrm{X}$ & & & & $\mathrm{X}$ & $\mathrm{X}$ & $\mathrm{X}$ \\
\hline Endoderme unisseriada com células de paredes com espessamento em "O" & & $\mathrm{X}$ & & & & & $\mathrm{X}$ & $\mathrm{X}$ & $\mathrm{X}$ \\
\hline Endoderme unisseriada com células de paredes com espessamento em "U" & & & $\mathrm{X}$ & & & & & & \\
\hline Endoderme unisseriada com células de paredes anticlinais espessadas & $\mathrm{X}$ & & & $\mathrm{X}$ & $\mathrm{X}$ & $\mathrm{X}$ & & & \\
\hline Periciclo unisseriado com células de paredes espessadas & $\mathrm{X}$ & $\mathrm{X}$ & & & & & & & \\
\hline Cilindro vascular com cerca de 11 pólos de protoxilema & $\mathrm{X}$ & $\mathrm{X}$ & $\mathrm{X}$ & & & & & & \\
\hline Cilindro vascular com cerca de 12 a 15 pólos de protoxilema & & & & $\mathrm{X}$ & $\mathrm{X}$ & $\mathrm{X}$ & & & $\mathrm{X}$ \\
\hline Cilindro vascular com cerca de 19 pólos de protoxilema & & & & & & & $\mathrm{X}$ & $\mathrm{X}$ & \\
\hline Medula com células parenquimáticas de paredes espessadas & $\mathrm{X}$ & $\mathrm{X}$ & $\mathrm{X}$ & $\mathrm{X}$ & $\mathrm{X}$ & $\mathrm{X}$ & $\mathrm{X}$ & $\mathrm{X}$ & $\mathrm{X}$ \\
\hline
\end{tabular}

como velame pluriestratificado, córtex diferenciado, endoderme e periciclo unisseriados, cilindro vascular poliarco e medula com células parenquimáticas de paredes espessadas. Essas estruturas caracterizam as espécies estudadas e também são citadas por Tomlinson (1969), Pita \& Menezes (2002), Segecin \& Scatena (2004), Proença \& Sajo (2008) para raízes de outras espécies de Bromeliaceae.

Em todas as raízes das espécies aqui estudadas ocorrem de velame pluriestratificado. Em representantes de Orchidaceae, Araceae, Bromeliaceae, Liliaceae, Dioscoriaceae, Taccaceae, Amarillidaceae e Comellinaceae o velame pode ser uniestratificado, biestratificado ou pluriestratificado (Fahn 1987, Mauseth 1988, Segecin \& Scatena 2004). Segundo esses autores as características que mais variam são: espessamento das paredes das células (forma e intensidade) e ausência de protoplasto vivo na maturidade das células situadas próximas à exoderme.

A existência de velame em raízes de várias espécies epíftas levou alguns autores a associarem sua presença ao hábito epifítico (Cutter 1980, Fahn 1987, Mauseth 1988). Como foi evidenciado velame também em raízes de Bromeliaceae terrestres, como Dyckia e Encholirium (Pita \& Menezes 2002), acredita-se que esse caráter pode estar relacionado mais ao fator genético do que ambiental.

Tomlinson (1969) descreveu para as Bromeliaceae epífitas a presença de raízes adventícias com função exclusiva de fixar a planta ao substrato. Nas espécies aqui estudadas ocorrem velame com pelos absorventes, que além de exercer papel protetor, também desempenham a função de absorver água. Dessa forma, nas espécies estudadas, as raízes exercem a função de fixação, suporte e absorção.

Nas paredes das células do velame das raízes das espécies estudadas ocorrem projeções sinuosas, que pode sugerir um aumento na superfície de absorção de água e sais minerais. Segundo Benzing et al. (1982) uma das funções do velame é exatamente a absorção. Para Esau (1977) e Fahn (1987) a função do velame é proteção mecânica e redução da perda de água através do córtex.

Na maioria das espécies estudadas a camada periférica do velame é diferenciada em epivelame com pelos absorventes. Essa característica também foi registrada para outros representantes de Bromeliaceae (Pita \& Menezes 2002, Segecin \& Scatena 2004, Proença \& Sajo 2008). Segundo Engard (1944) a presença de pelos absorventes está relacionada a condições ambientais especiais, inclusive do hábito da espécie. Acredita-se que nas espécies aqui estudadas, assim como naquelas estudadas por Segecin \& Scatena (2004), a presença de epivelame com pelos absorventes pode ser interpretada como estratégia das espécies para aumentar a superfície de absorção de água.

A exoderme das raízes das espécies estudadas varia de uniestratificada a pluriestratificada e sua presença pode 


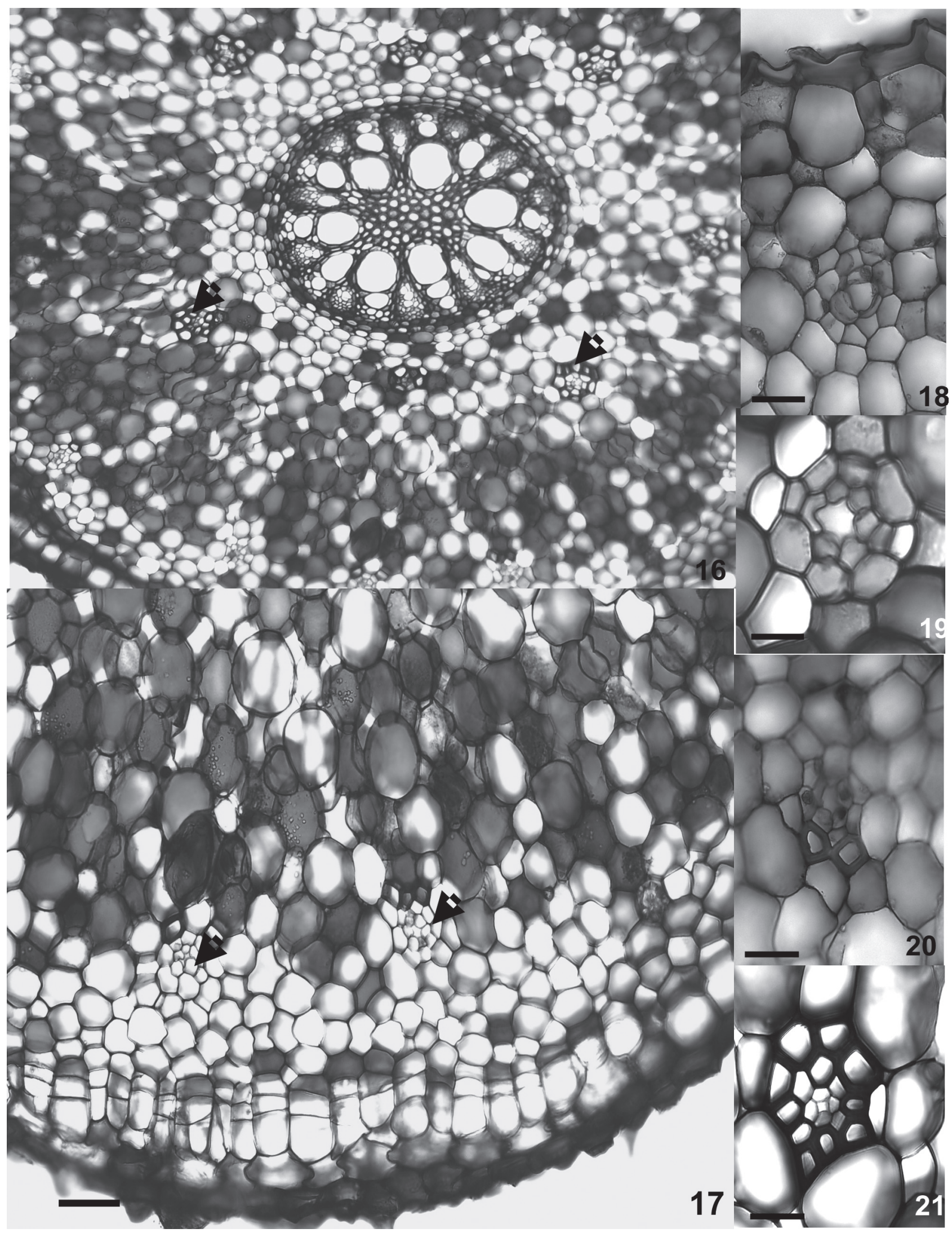

Figuras 16-21. Secções transversais de raízes de Aechmea castelnavii. 16. Aspecto geral. 17. Detalhe do felogênio e córtex com canais de mucilagem (setas). 18-21. Diferentes fases de desenvolvimento dos canais de mucilagem. 18-20. Raízes jovens. 21. Raiz adulta. (cabeças de setas- canais de mucilagem). Barras $=120 \mu \mathrm{m}$ (16); $130 \mu \mathrm{m}$ (17); $30 \mu \mathrm{m}(18-20) ; 25 \mu \mathrm{m}(19-21)$. 


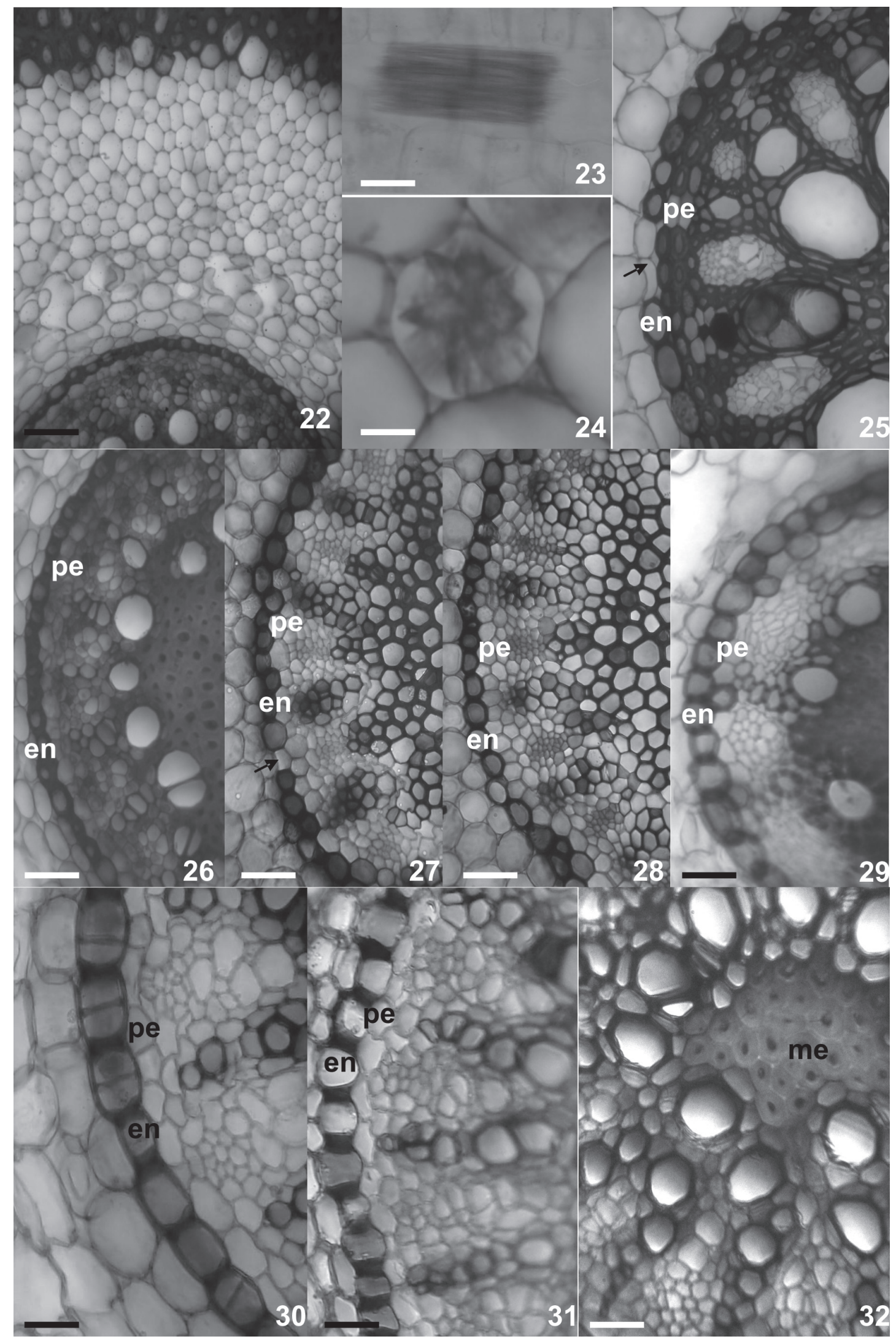

Figuras 22-32. Seç̧ões transversais de raízes de Bromeliaceae. 22. Aspecto do córtex externo, mediano e interno de Aechmea mertensii. 23. Detalhe de idioblasto com ráfides no córtex de Aechmea castelnavii. 24. Detalhe de idioblasto com drusa em Tillandsia didistachae. Detalhe da endoderme e cilindro vascular de: 25 . Aechmea castelnavii; 26. Aechmea mertensii; 27. Tillandsia adpressiflora; 28. Tillandsia didistachae; 29. Aechmea bromeliifolia; 30. Dyckia paraensis; 31-32. Dyckia duckei. (en-endoderme; me-medula; pe-periciclo) (setas- célula de passagem da endoderme). Barras = $110 \mu \mathrm{m}(22) ; 20 \mu \mathrm{m}(23-24) ; 40 \mu \mathrm{m}(25-31) ; 30 \mu \mathrm{m}(32)$. 
ser uma resposta contra a perda de água e maior proteção mecânica. Exoderme uniestratificada típica, com célulasde-passagem foi observada na grande maioria das raízes de Orchidaceae portadoras de velame (Withner et al. 1974, Benzing et al. 1982, Pridgeon \& Stern 1982, Stern \& Whitten 1998, Stern \& Judd 2001, Stern et al. 2004). Já em espécies de Bromeliaceae (Pita \& 257 Menezes 2002, Segecin \& Scatena 2004, Proença \& Sajo 2008) é comum a presença de uma exoderme pluriestratificada.

Uma das funções atribuídas à exoderme é a diminuição da transpiração da raiz, conforme observado em orquídeas por Sanford \& Adalawo (1973) e Benzing et al. $(1982,1983)$. Segundo Tomlinson (1969) e Dycus \& Knudson (1957), o conjunto velame-exoderme oferece proteção mecânica e dificulta a perda de água do córtex radicular, sendo também capaz de armazenar água e nutrientes.

Nas plantas que possuem raízes aéreas as células da exoderme podem apresentar somente paredes primárias (Sanford \& Andalawo 1973, Pita \& Menezes 2002). A forma, o tamanho e principalmente o grau de espessamento das paredes das células do velame e da exoderme, variam em função da umidade relativa do ar (Sanford \& Adalawo 1973, Dycus \& Knudson 1957). Como a maioria das espécies estudadas apresenta raízes com células exodérmicas de paredes totalmente espessadas, acredita-se que essa camada mecânica propicia uma diminuição da transpiração e uma fixação mais eficiente. Verifica-se que as espécies rupícolas apresentam raízes com tecidos formados por células de paredes mais espessas do que as epífitas de árvores devido á rigidez do substrato.

Em todas as raízes das espécies estudadas é possível diferenciar córtex externo, mediano e interno, caráter também observado para as Bromeliaceae em geral (Tomlinson 1969). Segundo o autor, o córtex externo apresenta células de paredes espessadas, o córtex mediano possui células de paredes delgadas e o córtex interno, células com paredes delgadas, espaços intercelulares evidentes e canais de ar. De acordo com Meyer (1940 apud Tomlinson 1969) os espaços intercelulares presentes no córtex interno das raízes de Bromeliaceae têm a função de transportar água por capilaridade. Os canais de ar ocorrentes no córtex interno das raízes das espécies aqui estudadas, possivelmente, desempenham a função de transportar a água por capilaridade conforme sugerido por Meyer (apud Tomlinson 1969), para outras Bromeliaceae e pode ser uma resposta adaptativa ao hábito epifítico.

A presença de idioblastos contendo cristais do tipo ráfides e drusas nas raízes das espécies estudadas, pode ser interpretada como sinapomorfia da família, uma vez que sua ocorrência é relatada para todas as Bromeliaceae estudadas até o momento. Para Poales em geral, a presença de idioblastos de cristais foi sugerida como caráter plesiomórfico (Proença \& Sajo 2008). Além disso, acredita-se que esse caráter pode ser considerado como resposta adaptativa das plantas às condições xerofíticas (Fahn \& Cuttler 1992) e também pode atuar na prevenção contra ataque de herbívoros (Prychid \& Rudall 2000).
Na literatura consultada não foi documentado canal de mucilagem nas raízes de Bromeliaceae, mas neste trabalho, foi observada em Aechmea castelnavii. De acordo com Esau (1977), a presença de mucilagem nos tecidos, além de evitar a dessecação, também atua na troca iônica possibilitando a quelagem dos nutrientes e segundo Fahn \& Cutler (1992) é considerada como adaptação das plantas às condições xerofíticas. Para A. castelnavii acredita-se que os canais possuam essas funções, estando associado ao hábito epifítico e servindo como diagnóstico para a espécie. Alem dos canais de mucilagem, a presença de felogênio nas raízes adultas de A. castelnavii também é considerada caractere diagnóstico.

As espécies aqui estudadas apresentam raízes com endoderme e periciclo unisseriados, características também relatadas para outras espécies do gênero (Pita \& Menezes 2002, Segecin \& Scatena 2004). Para a maioria das raízes de Bromeliaceae estudadas indica-se a presença de endoderme com células pequenas de paredes delgadas. Nas espécies aqui estudadas que ocorrem na região amazônica e apresentam hábito epífita e rupícola, talvez o espessamento de suas paredes seja resposta adaptativa ao ambiente, conforme observado por Segecin \& Scatena (2004) e Proença \& Sajo (2008).

Dentre as espécies estudadas, as raízes de Dyckia e Tillandsia apresentam maior número de caracteres comuns (Tab. 1) e portanto, a semelhança anatômica entre as subfamílias Pitcairnioideae e Tillandsioideae é mais evidenciada. Em outras espécies de Dyckia e Tillandsia estudadas (Tomlinson 1969, Segecin \& Scatena 2004, Proença \& Sajo 2008) essa semelhança também foi observada indicando caracteres consistentes para os gêneros. Talvez, por essa razão, Tillandsioideae não tenha sido reconhecida como grupo monofilético.

Nas Tillandsia analisadas a presença de velame, exoderme e endoderme com paredes periclinais e anticlinais espessadas, presença de idioblasto com ráfides e drusas, presença de canais de ar, periciclo de células de paredes delgadas e medula com células de paredes espessadas são caracteres comuns e também encontrados nas outras espécies do gênero (Tomlinson 1969, Segecin \& Scatena 2004, Proença \& Sajo 2008).

Tillandsia paraensis difere das demais espécies de Tillandsia aqui estudadas por apresentar velame com seis camadas de células, exoderme com quatro camadas de células e protoxilema com cerca de 12 pólos. Tillandsia adpressiflora e T. didistachae compartilham entre si a maioria dos caracteres anatômicos, com a diferença que em T. adpressiflora as células do velame apresentam paredes espessadas. Para Tomlinson (1969) o conjunto, velame, exoderme de paredes espessadas e cilindro vascular com muitos elementos de condução está ligado ao hábito epifítico e também foram observadas em outras espécies estudadas (Segecin \& Scatena 2004, Proença \& Sajo 2008).

As raízes das espécies de Dyckia estudadas apresentam pouca diferença anatômica. Dyckia duckei apresenta três camadas de células da exoderme e as demais apresentam quatro. $D$. racemosa apresenta sete camadas de células de velame enquanto as demais apresentam dez. Essa diferença 
também foi observada por Pita \& Menezes (2002) em outras espécies de Dyckia.

Das espécies estudadas, as de Aechmea apresentam maior variação dos caracteres anatômicos das raízes. Essa maior variação pode estar ligada à ocorrência de seus representantes em maior diversidade de habitat. O espessamento helicoidal da parede das células do velame é um caráter que possibilita diferenciar A. mertensii de A. bromeliifolia e $A$. castelnavii. Enquanto que presença de canais de mucilagem, felogênio e periciclo com células de paredes espessadas distinguem A. castelnavii das demais. Esses caracteres são considerados importantes na delimitação dessas espécies.

As espécies de Aechmea estudadas se caracterizam por apresentar idioblastos contendo cristais e cilindro vascular com cerca de 11 pólos de protoxilema, enquanto que as de Dyckia apresentam velame com sete a dez camadas de células, exoderme pluriestratificada com espessamento homogêneo, endoderme com células de paredes anticlinais espessadas e cilindro vascular com cerca de 12-15 pólos de protoxilema, e as de Tillandsia velame com cinco a seis camadas de células, exoderme pluriestratificada com espessamento de parede homogêneo, idioblasto contendo cristais e endoderme com espessamento de parede em "O".

\section{Agradecimentos}

À Fundação de Amparo à Pesquisa do estado de Mato Grosso (FAPEMAT), pelo auxílio à pesquisa (732482/2008). Ao CNPq pela bolsa de produtividade em pesquisa à segunda autora (processo 302105/2007-7).

\section{Referências Bibliográficas}

Barfuss, M.H.J.; Samuel, R.; Till, W. \& Stuessy, T.F. 2005. Phylogenetic relationships in subfamily Tillandsioideae (Bromeliaceae) based on DNA sequence data from seven plastid regions. American Journal of Botany 92: 337-351.

Benzing, D.H.; Ott, D.W. \& Friedman, W.E. 1982. Roots of Sobralia macrantha (Orchidaceae): structure and function of the velamen-exodermis complex. American Journal of Botany 69(4): 608-614.

Benzing, D.H.; Friedman, W.E.; Peterson, G. \& Renfrow, A. 1983. Shootlesness, velamentous roots, and the permanence of Orchidaceae in the epiphytic biotope. American Journal of Botany 70: 121-133.

Benzing, D.H. 2000. Bromeliaceae: profile of an adaptative radiation. Cambridge, Cambridge University Press.

Brown G. K. \& Terry, R. G. 1992. Petal appendages in Bromeliaceae. American Journal of Botany 79: 1051-1071.

Costa, A.F. 1972. Farmacognosia (Farmacognosia Experimental). Lisboa, Fundação Calouste Gulbenkian.

Costa, S.M.O.; Lemos, T.L.G.; Deusdênia, O.; Pessoa, L.; Assunção, J.C.C. \& Braz-Filho, R. 2002. Constituintes químicos de Lippia sidoides (Cham.) Verbenaceae. Revista Brasileira de Farmacognosia 12: 66-67.

Cutter, E.G. 1980. Plant anatomy. Part II: organs. London, Edward Arnold.

Dahlgren, R.M.T.; Clifford, H.T. \& Yeo, P.F. 1985. The families of the monocotyledons. Berlin, Springer-Verlag.

Dycus, A.M. \& Knudson, L. 1957. The role of the velamen of the aerial roots of orchids. Botanical Gazette 119: 78-87.
Engard, C.J. 1944. Morphological identity of the velamen and exodermis in orchids. Botanical Gazette 105: 457-462.

Esau, K. 1977. Anatomy of seed plants. 2 ed. New York, John Wiley \& Sons.

Fahn, A. 1987. Plant anatomy. 3 ed. Oxford, Pergamon Press.

Fahn, A. \& Cuttler, D.F. 1992. Xerophytes. Encyclopedia of plant taxonomy. Berlin, Gebruder Borntraeger.

Givnish, T.J.; Pires, J.C.; Graham, S.W.; Mcpherson, M. A.; Prince, L.M. \& Patterson, T.B. 2008. Phylogeny, biogeography, and ecological evolution in Bromeliaceae: Insights from ndhF sequences. Pp. 3-26. In: Columbus, J.T.; Friar, E.A.; Porter, J.M.; Prince, L.M. \& Simpson, M.G. (Eds), Monocots: Comparative Biology and Evolution. Claremont, Rancho Santa Ana Botanical Garden.

Horres, R.; Zizka, G.; Kahl, G. \& Weising, K. 2000. Molecular phylogenetics of Bromeliaceae: evidence from $\operatorname{tr} n \mathrm{~L}$ (UAA) intron sequences of the chloroplast genome. Plant Biology 2: 306-315.

Johansen, D.A. 1940. Plant microtechnique. New York, McGraw-Hill Book Co. Inc.

Kaiser, E. 1880. Verfahren zur Herstellung einer tadellosen GlycerinGelatine. Botanisch zentralb 1880: 25-26.

Krauss, B.H. 1948. Anatomy of the vegetative organs of the Pineapple, Annanas comosus (L.) Merr. Botanical Gazette 110: 159-217.

Krauss, B.H. 1949. Anatomy of the vegetative organs of the pineapple, Ananas comosus (L.) Merr. III - The root and the cork. Botanical Gazette 110: 550-587.

Langeron, M. 1949. Precis de Microscopie. Paris, Masson et Ciencie.

Luther, H.E. 2006. An alphabetical list of bromeliad binomial. 10 ed. Sarasota, The Marie Selby Botanical Gardens.

Mauseth, J.D. 1988. Plant anatomy. San Francisco, The Benjamin Cummings Publishing Company, Inc.

Pita, P.B. \& Menezes, N.L. 2002. Anatomia da raiz de espécies de Dyckia Schult. f. e Encholirium Mart. ex Schult. \& Schult. f. (Bromeliaceae, Pitcairnioideae) da Serra do Cipó (Minas Gerais, Brasil), com especial referência ao velame. Revista Brasileira de Botânica 25(1): 25-34.

Pridgeon, A.M. \& Stern, W.L. 1982. Vegetative Anatomy of Mioxanthus (Orchidaceae). Selbyana 7(1): 55-63.

Prychid, C.J. \& Rudall, P.J. 2000. Distribution of calcium oxalate crystals in monocotyledons.Pp. 159-162. In: Wilson, K.L. \& Morrison, D.A. (Eds.). Monocots: Systematics and Evolution. Melbourne, Csiro Publishing.

Proença, S.L. \& Sajo, M.G. 2008. Rhizome and root anatomy of 14 species of Bromeliaceae. Rodriguésia 59(1): 113-128.

Roeser, K.R. 1962. Die Nadel der Schwarzkiefer-Masenprodukt und Keinstwert der Natur. Microkosmos 61: 33-36.

Sanford, W.W. \& Adanlawo, I. 1973. Velamen and exodermis characters of west african epiphytic orchids in relation to taxonomic grouping and habitat tolerance. Botanical Journal of the Linnean Society 66: 307-321.

Segecin, S. \& Scatena, V.L. 2004. Morfoanatomia de rizomas e raízes de Tillandsia L. (Bromeliaceae) dos Campos Gerais, PR, Brasil. Acta Botanica Brasilica 18(2): 253-260.

Smith, L.B. \& Downs, R.J. 1974. Pitcairnioideae (Bromeliaceae). Flora Neotropica Monograph 14: 1-662.

Stevens, P.F. 2008. Angiosperm Phylogeny Website. Version 9, June 2008. [and more or less continuously updated since]." will do. http://www. mobot.org/ MOBOT/research/Apweb/.

Stern, W.L. \& Whitten, W.M. 1998. Comparative vegetative anatomy of Stanhopeinae (Orchidaceae). Botanical Journal of the Linnean Society 129: 87-103.

Stern, W.L. \& Judd, W.S. 2001. Comparative anatomy and systematic of Catasetinae (Orchidaceae). Botanical Journal of the Linnean Society 136: $153-178$

Stern, W.L., Judd, W.S. \& Carlsward, B.S. 2004. Systematic and comparative anatomy of Maxillarieae (Orchidaceae), sans Oncidiinae. Botanical Journal of the Linnean Society 144: 251-274.

Tomlinson, P.B. 1969. III- Commelinales-Zingiberales. In: METCALFE, C.R. (Ed.). Anatomy of the Monocotyledons. Oxford, Clarendon Press.

Withner, C.L., Nelson, P.K. \& Wejksnora, P.J. 1974. The anatomy of Orchids. In: Wither, C.L. The Orchids Cientific Studies. New York, John Wiley. 